\title{
Targeted therapy for gastric cancer: Current status and future directions (Review)
}

\author{
DAN-DAN YUAN ${ }^{1}$, ZHONG-XIU ZHU $^{2}$, XIA ZHANG $^{1}$ and JIE LIU ${ }^{1}$ \\ ${ }^{1}$ Department of Internal Oncology, Shandong Cancer Hospital and Institute, Shandong Academy of \\ Medical Sciences, Jinan, Shandong 250117; ${ }^{2}$ Department of Internal Oncology Ward 7, Affiliated \\ Hospital of Shandong Academy of Medical Sciences, Jinan, Shandong 250031, P.R. China
}

Received October 7, 2015; Accepted November 18, 2015

DOI: $10.3892 / o r .2015 .4528$

\begin{abstract}
According to the 2012 statistics of the International Agency for Research on Cancer (IARC), gastric cancer is the fifth most common malignancy, and the third leading cause of cancer-related deaths worldwide. Conventional chemotherapy and radiation have shown limited efficacy for advanced gastric cancer, showing an overall survival (OS) rate of $\sim 10$ months. Trastuzumab, a monoclonal antibody against human epidermal growth factor receptor 2 (HER2), is the first approved molecularly targeted agent for HER2-overexpressing gastric cancer, which was found to prolong the OS and the progression-free survival (PFS) of patients. However, HER2 overexpression is present only in a minority of patients with gastric cancer. Hence, other targeted agents are urgently needed. Ramucirumab, a novel human IgG1 monoclonal antibody that selectively targets the extracellular domain of VEGF receptor 2 (VEGFR2), is regarded as a new standard secondline treatment for patients with advanced gastric cancer. The combination of two or more targeted agents directed against two different molecular targets may improve the survival of
\end{abstract}

Correspondence to: Dr Jie Liu, Department of Internal Oncology, Shandong Cancer Hospital and Institute, Shandong Academy of Medical Sciences, 440 Jiyan Road, Jinan, Shandong 250117, P.R. China

E-mail: 1j691012@126.com

Abbreviations: OS, overall survival; HER2, human epidermal growth factor receptor 2; PFS, progression-free survival; mTOR, mammalian target of rapamycin; TKIs, tyrosine kinase inhibitors; EGFR, epidermal growth factor receptor; HR, hazard ratio; NCCN, National Comprehensive Cancer Network; ORR, objective response rate; DCR, disease control rate; GEJ, gastroesophageal junction; pCR, pathological complete response; TTP, time to progression; $\mathrm{CR}$, complete response; SD, stable disease; AEs, adverse events; FISH, fluorescence in situ hybridization; OR, odds ratio; IHC, immunohistochemistry; PI3K, phosphatidylinositol 3-kinase; HGF, hepatocyte growth factor; GEC, gastroesophageal adenocarcinoma

Key words: anti-EGFR, anti-mTOR, anti-VEGF, gastric cancer, targeted therapy patients with advanced gastric cancer. Although great efforts have been made, the effect of targeted therapy for gastric cancer is limited. One key reason is that participants in clinical trials for new targeted agents were not selected by detection of the targeted molecule. Here, we review clinical trials related to molecular targets such as anti-epidermal growth factor receptor signaling including anti-HER2 and anti-EGFR1, anti-VEGF signaling, anti-mammalian target of rapamycin (mTOR), tyrosine kinase inhibitors (TKIs) and anti-MET.

\section{Contents}

1. Introduction

2. Anti-EGFR signaling

3. Anti-VEGF signaling

4. Tyrosine kinase inhibitors

5. mTOR inhibitors

6. Anti-MET pathway

7. Other target agents and future directions

8. Conclusions

\section{Introduction}

Gastric cancer remains a major health burden across the globe. According to the 2012 statistics of the International Agency for Research on Cancer (IARC), it was estimated that almost one million new cases of gastric cancer were diagnosed in 2012 (952,000 cases, $6.8 \%$ of the total), making it the fifth most common malignancy worldwide after cancers of the lung, breast, colorectal and prostate. Gastric cancer is the third leading cause of cancer-related deaths in both genders worldwide (723,000 deaths, $8.8 \%$ of the total), and the third leading cause of cancer-related deaths in China (1). Surgery is the only curative treatment strategy for relatively early staged gastric cancer, but for patients in an advanced stage, overall survival (OS) is poor at $\sim 10$ months for those who receive conventional chemotherapy. Chemotherapy is the most common therapy for advanced gastric cancer, but efficacy is limited. Targeted therapy, as a new strategy, may improve the survival of advanced gastric cancer patients. Here, we review the clinical trials related to targeted therapies for gastric 
cancer, such as anti-EGFR signaling including anti-human epidermal growth factor receptor 2 (HER2) and anti-EGFR1, anti-VEGF signaling, anti-mTOR, tyrosine kinase inhibitors (TKIs) and anti-MET.

\section{Anti-EGFR signaling}

The epidermal growth factor receptor (EGFR/HER1) belongs to a receptor tyrosine kinase protein family that includes HER 2/neu, HER3 and HER4 (2). When binding to ligands, EGFR family members form homodimers or heterodimers with different biological effects (3). Activation of EGFR can lead to diverse cellular biological processes, including cell proliferation, migration, differentiation, survival and transformation $(4,5)$. The EGFR signaling pathways have been found to be activated in many types of cancers, particularly head and neck, lung and colorectal cancer. In esophagogastric adenocarcinoma, EGFR overexpression has been reported in $27-55 \%$ of cases $(6,7)$, and has been associated with reduced OS in various series $(6,8)$. Hence, drugs targeting EGFR may be potential therapeutic targeted agents.

Trastuzumab. Trastuzumab is the first approved molecular targeted agent for gastric cancer patients. It is a monoclonal antibody against human EGFR2 (HER2; also known as ERBB2) by binding to the extracellular domain of the receptor. A well-known milestone-like phase III clinical trial was the Trastuzumab for Gastric Cancer (ToGA) trial. It enrolled 594 gastric cancer patients with HER2 overexpression, who were randomized to chemotherapy or chemotherapy in combination with trastuzumab (9). Trastuzumab treatment showed an increased OS of 2.7 months, from 11.1 to 13.8 months [hazard ratio $(\mathrm{HR})=0.74 ; \mathrm{p}=0.0046]$. Due to the results, the National Comprehensive Cancer Network (NCCN) guideline in 2013 referenced the results of the ToGA trial. The recent update of NCCN Guidelines Version 3.2015 Gastric Cancer clearly recommended that trastuzumab can be added to first-line chemotherapy for HER-neu overexpressing adenocarcinoma.

The efficacy of combination treatment with trastuzumab and XELOX in the first-line therapy for 55 HER2-positive advanced gastric cancer patients in a phase II trial was studied in Korea (10). The primary endpoint was the objective response rate (ORR), and secondary endpoints included progression-free survival (PFS), OS and toxicity. The ORR was $67 \%$ (95\% CI, 54-80). The median PFS and OS were 9.8 months $(95 \% \mathrm{CI}$, 7.0-12.6) and 21.0 months (95\% CI, 6.4-35.7), respectively. The most common grade 3-4 toxicities included neutropenia (18\%), anaemia (11\%) and peripheral neuropathy (11\%). The trial showed that a combination of trastuzumab and XELOX was well tolerated and was highly effective in patients with HER2-positive advanced gastric cancer. Similar results from a phase II trial in Singapore found that a combination of trastuzumab with S-1 and cisplatin demonstrated good activity, was well tolerated, and is a feasible treatment option in the firstline treatment of HER2-positive advanced gastric/gastric or gastroesophageal junction (GEJ) cancers (11).

Panitumumab. Panitumumab is a fully human immunoglobulin G2 monoclonal antibody against EGFR, and it has been proven to bring survival benefits for advanced colorectal cancer patients (12). Several clinical trials concerning panitumumab have been conducted. REAL3, a randomized, open-label phase III trial, enrolled 553 eligible gastric cancer patients. The modified EOC (epirubicin, oxaliplatin and capecitabine) + panitumumab group showed a shorter median OS (8.8 vs. 11.3 months), compared with the EOC group $(\mathrm{HR}=1.37 ; 95 \% \mathrm{CI}, 1.07-1.76 ; \mathrm{p}=0.013)$. While the combination with panitumumab showed an increased incidence of grade 3-4 diarrhea, rash, mucositis and hypomagnesemia (13). The patients in the trial were not selected by an immunohistchemistry test for EGFR expression.

A phase II trial to assess the efficacy and safety of panitumumab combined with docetaxel and cisplatin as a first-line treatment for advanced unresectable or metastatic GEJ adenocarcinoma (NCT01379807) is ongoing. The primary endpoint is ORR. The secondary endpoints include disease control rate (DCR), duration of response, time to response, time to progression and OS. The present study is not recruiting participants.

In order to ascertain whether panitumumab in combination with epirubicin, cisplatin and capecitabine (ECX) will safely decrease the frequency of pT3/T4 below that of ECX alone in locally advanced adenocarcinoma of the stomach and GEJ (stage uT/ 3 or $4 \mathrm{N0} /{ }^{+}$and $\mathrm{M} 0$ disease evaluated by endoscopic ultrasound, spiral computed tomography of the chest, abdomen and pelvis and by laparoscopy in uT3/T4 tumors), an open label randomized controlled phase II trial of panitumumab in combination with ECX vs. ECX alone in locally advanced gastric cancer or cancer of the GEJ was conducted (NCT01234324). The primary endpoint was the frequency of pT3/T4 categories after surgery, and the secondary endpoint was the frequencies of $\mathrm{pN} 2 / \mathrm{N} 3$ categories after surgery. The present study is ongoing, but not recruiting participants.

To study the effect of panitumumab when combined with docetaxel, cisplatin and fluourouracil (DCF), in previously untreated patients with advanced cancer of the stomach, a phase I/II, multicenter, single-arm clinical trial is ongoing (NCT01716546). The primary endpoint is ORR, secondary endpoints include PFS and OS. The present study is currently recruiting participants.

In order to assess the safety and efficacy of panitumumab in perioperative treatment for the esophagus and stomach, a pilot study of perioperative panitumumab with epirubicin, oxaliplatin and capecitabine (EOX) in patients with adenocarcinoma of the esophagus and stomach [AJCC stage II-IIIB (gastric) or IIA-IVA (esophageal), included M1a disease but not T4 lesions] was conducted (NCT00667420). The primary endpoint was safety and tolerability, and secondary endpoints were R0 resection rate, pathological complete response (pCR) and OS. The present study has been terminated due to slow accrual.

Cetuximab. Cetuximab is a monoclonal $\operatorname{IgG}$ antibody targeting EGFR through binding to the extracellular domain of EGFR in an inactive form and competes for receptor binding by blocking the ligand-binding region. In addition, it is used for the treatment of metastatic colorectal, metastatic non-small cell lung, and head and neck cancer. A prospective multicenter phase II trial of cetuximab was conducted in non-treated advanced gastric or GEJ adenocarcinoma. The ORR, median PFS and OS of cetuximab combined 
with cisplatin and capecitabine group was $53.2 \%, 5.2$ and 10.8 months, respectively. The efficacy was correlated with the severity of skin rash and the TGF- $\alpha$ level, while EGFR overexpression may predict cetuximab efficacy (14). An open-label randomized phase III trial (EXPAND) showed that the median PFS was 4.4 months (95\% CI, 4.2-5.5) in a capecitabine-cisplatin plus cetuximab group and 5.6 months (95\% CI, 5.1-5.7) in a capecitabine-cisplatin alone group (HR=1.09; 95\% CI, 0.92-1.29; p=0.32). Hence, cetuximab could not bring additional benefit to advanced gastric cancer patients receiving chemotherapy in the first-line treatment (15).

Results from the REAL3 and EXPAND trials suggested that the anti-EGFR antibody could not provide additional benefit for advanced gastric cancer patients, but brought worse results. The reason may be that the anti-EGFR antibody could not interact with the chemotherapy in gastric cancer. In addition, in the EXPAND trial the EGFR immunochemistry (IHC) score was not correlated with the efficacy.

Nimotuzumab. Nimotuzumab is the first humanized EGFR monoclonal antibody that binds to the extracellular region of EGFR firmly and specifically. This results in a blockade of ligand-receptor binding and activation. A phase II clinical trial of nimotuzumab enrolled 34 reoccurrence or metastatic patients with late-stage gastric cancer. The standard DCF (taxotere, cisplatin and FU) plan was administered to patients in the control group, while additionally nimotuzumab was administered to patients in observational group. ORR and DCR were 64.7 and $82.4 \%$ in the nimotuzumab combined with DCF group, and 25.0 and $37.5 \%$ in the control group; the median PFS and OS were 6.50 and 12.50 months in the observational group and 4.50 and 8.25 months in the control group ( $\mathrm{p}=0.0212$ and $\mathrm{p}=0.0255$, respectively) (16). No differences in the occurrence of toxic and side-effects between the two groups were observed. Although this study indicated that nimotuzumab combined with DCF plan is effective for late stage gastric cancer, a large number of participants are needed.

To assess the efficacy and safety of the addition of nimotuzumab to cisplatin and S-1 (CS) chemotherapy in patients with previously untreated advanced gastric adenocarcinoma, a single-center, randomized, open-label, parallel-group, controlled phase II clinical trial (NCT02370849) was conducted. Sixty-two patients were randomly assigned (1:1) to each group. The control regime was CS chemotherapy and the observed regimen was nimotuzumab plus CS. The primary outcome was ORR, and the secondary outcomes were time to progression (TTP), PFS, treatment safety and toxicity. The present study has been completed. Results are expected.

As we know, when patients fail from the first-line regimen containing a 5-fluorouracil and platinum-based agent, second-line chemotherapy agents should include a irinotecanbased regimen. A randomized, open-label, Japan-Korea collaborative phase III study to compare the efficacy of a combination therapy of nimotuzumab and irinotecan vs. irinotecan monotherapy as second-line treatment in EGFRoverexpressing advanced or recurrent gastric and GEJ cancer, who failed from the first-line regimen contained a 5-fluorouracil- and platinum-based agent is underway (NCT01813253). Approximately 400 subjects will be randomized in a 1:1 ratio to receive irinotecan (control group) or nimotuzumab and irinotecan (combination group). The primary endpoint is OS, and secondary endpoints are PFS, ORR, DCR and incidence of adverse events. The present study is currently recruiting participants.

\section{Anti-VEGF signaling}

Tumor-associated neovascular, generated by the process of angiogenesis, supply the requirement of sustenance in the form of nutrients and oxygen as well as an ability to evacuate metabolic wastes and carbon dioxide (17). Angiogenesis is now considered as one of the hallmarks of cancer progression (18). Tumor angiogenesis is mediated by tumor-secreted angiogenic growth factors (such as VEGF and bFGF) that interact with their surface receptors expressed on endothelial cells. Activation of VEGF includes ligand binding to the extracellular domain of transmembrane tyrosine kinase receptor which induces the autophosphorylation of an intracellular kinase domain and then subsequent downstream signaling by kinases (17). At present antiangiogenic therapy is an attractive modality for preventing the development of malignant neoplasms (19).

Bevacizumab. Bevacizumab is a humanized IgG1 monoclonal antibody directed against VEGF, preventing the binding to receptors thereby inhibiting the VEGF/VEGF receptor signaling pathway (20). A phase II study of capecitabine, oxaliplatin and bevacizumab for the treatment of metastatic esophagogastric adenocarcinoma was conducted (21). Thirty-five patients were evaluable for efficacy. Median PFS and OS were 7.2 and 10.8 months. The response rate (RR) was $51.4 \%$. The expected drug-related toxicities of the regimen were tolerable. In the trial, the NRP2 mRNA levels were found to be significantly correlated with PFS $(\mathrm{p}=0.042)$ and showed a trend toward significance with $\mathrm{OS}(\mathrm{p}=0.051)$.

The AVAGAST trial of a combination bevacizumab with cisplatin and capecitabine in 774 patients demonstrated an improvement in PFS and RR, but failed to meet its primary endpoint of OS (22). In the trial, patients received bevacizumab $7.5 \mathrm{mg} / \mathrm{kg}$ or placebo followed by cisplatin and capecitabine every 3 weeks. Median OS was 12.1 vs. 10.1 months ( $p=0.1002$ ) in the bevacizumab plus fluoropyrimidine-cisplatin group vs. the placebo plus fluoropyrimidine-cisplatin group. Both median PFS (6.7 vs. 5.3 months; $\mathrm{p}=0.0037$ ) and ORR (46.0 vs. $37.4 \%$; $\mathrm{p}=0.0315$ ) were significantly improved in the bevacizumab group compared with the placebo group.

Van Cutsem et al evaluated the prognostic biomarkers in the AVAGAST trial (23). The baseline plasma VEGF-A levels and tumor neuropilin-1 expression were found to be potential predictors of bevacizumab efficacy. Higher baseline plasma VEGF-A levels or lower baseline expression of neuropilin-1 was associated with an improved trend of OS. For both biomarkers, subgroup analyses demonstrated significance only in patients from non-Asian regions. Recently, Shen et al conducted a randomized, double-blind, phase III study (AVATAR study) to evaluate the efficacy of bevacizumab plus capecitabine and cisplatin in Chinese patients with inoperable locally advanced or metastatic gastric or GEJ cancer (24); 202 patients were included (102 to placebo; 100 to bevacizumab group). The results did not show a difference in OS or PFS 
for the bevacizumab arm compared with the placebo arm. Bevacizumab plus capecitabine-cisplatin was well tolerated. Grade 3-5 adverse events (AEs) of special interest with bevacizumab occurred in $8 \%$ of the bevacizumab-treated patients and $15 \%$ of placebo-treated patients, mainly grade 3-5 hemorrhage (bevacizumab $4 \%$, placebo $12 \%$ ).

Ramucirumab. Ramucirumab is a novel human $\mathrm{IgG} 1 \mathrm{mAb}$ that selectively targets the extracellular domain of VEGF receptor 2 (VEGFR2) and blocks the VEGFR2-related downstream signaling activation. A phase I trial of ramucirumab reported that the maximum tolerated dose was $13 \mathrm{mg} / \mathrm{kg}$, and $60 \%$ of patients developed grade 3 or higher toxicity with fatigue, nausea/vomiting, proteinuria and hypertension (25).

The REGARD trial was an international, placebocontrolled, double-blind trial (NCT00917384) that evaluated the efficacy and safety of ramucirumab monotherapy in patients with metastatic gastric or GEJ cancer following standard first-line treatment with platinum or fluoropyrimidine-based therapy. A total of 355 patients were randomized (2:1) to $8 \mathrm{mg} / \mathrm{kg}$ or placebo every 2 weeks in combination with best supportive care. The trial met its primary endpoint, OS. Ramucirumab demonstrated an improved OS ( $\mathrm{HR}=0.78$; $\mathrm{p}=0.047$ ), with a median OS of 5.2 vs. 3.8 months in the ramucirumab vs. the placebo group. Six- and 12-month survival rates were 42 vs. $32 \%$, and 18 vs. $11 \%$, respectively, in the ramucirumab vs. placebo arms. PFS was also significantly prolonged $(\mathrm{HR}=0.48)$, with median PFS from 1.3 to 2.1 months with ramucirumab, as well as 12-week PFS (40 vs. 16\%) (26). Unlike the AVAGAST study, the REGARD study chose patients who failed first-line therapy and involved more non-Asian patients. As we know in AVAGAST, Asian patients benefitted little. The success of the study may have been attributed to its design.

Based on the activity of taxanes in second-line gastric cancer, the RAINBOW phase III trial was conducted at 170 centers in 27 countries (27). The trial evaluated paclitaxel with or without ramucirumab for patients with metastatic refractory gastric cancer (NCT01170663). The primary endpoint was OS. A total of 665 patients (330 to ramucirumab plus paclitaxel; 335 to placebo plus paclitaxel) were enrolled. Median OS was significantly longer in the ramucirumab plus paclitaxel group than in the placebo plus paclitaxel group (9.6 vs. 7.4 months, $\mathrm{HR}=0.807 ; 95 \% \mathrm{CI}, 0.678-0.962 ; \mathrm{p}=0.017)$. Grade 3 or higher AEs that occurred in $>5 \%$ of patients in the ramucirumab plus paclitaxel group vs. the placebo plus paclitaxel included higher neutropenia (41 vs. 19\%), leucopenia (17 vs. 7\%), hypertension (14 vs. $2 \%$ ) and fatigue (12 vs. 5\%). Based on the above results, the combination of ramucirumab with paclitaxel significantly increased OS compared with placebo plus paclitaxel, and could be regarded as a new standard second-line treatment for patients with advanced gastric cancer.

In the 2014 ASCO meeting, an oral presentation was made on a randomized, double-blind, multicenter phase II study of ramucirumab plus FOLFOX as front-line therapy $(\mathrm{Rx})$ for advanced gastric or esophageal adenocarcinoma (GE-AC). The primary endpoint was PFS, which was 6.44 months in the ramucirumab plus FOLFOX group vs. 6.74 months in the placebo plus FOLFOX group ( $\mathrm{HR}=0.98 ; 95 \% \mathrm{CI}, 0.69-1.37)$; OS in the RAM plus FOLFOX group was 11.7 vs. 11.5 months in the placebo plus FOLFOX group $(\mathrm{HR}=1.08 ; 95 \% \mathrm{CI}$, $0.73-1.58)$. The trial indicated that the addition of ramucirumab to FOLFOX did not improve PFS in first-line therapy for advanced gastric or esophageal adenocarcinoma (28). Hence, ramucirumab is used as a second-line treatment.

\section{Tyrosine kinase inhibitors}

Molecularly targeted therapies with tyrosine kinase inhibitors (TKIs) are designed to disrupt signaling pathways responsible for the abnormal proliferation of cancer cells. Progress in the development of molecularly targeted agents for TKIs has expanded the treatment options for patients with several types of cancers, such as lung cancer $(29,30)$, renal cell (31) and hepatocellular carcinoma $(32,33)$.

Sorafenib. Sorafenib is a multitarget inhibitor of BRAF, VEGF, PDGFR and the Ras/Raf/MERK/ERK pathway. A phase II study evaluated the efficacy and toxicity of the combination of sorafenib and oxaliplatin as second-line therapy. A total of 40 patients were included. Complete response (CR) was $2.5 \%$ and stable disease (SD) was $47.2 \%$. Grade $3-4$ toxic effects were neutropenia $(9.8 \%)$, thrombocytopenia $(7.3 \%)$, neurotoxicity (4.9\%) and diarrhea (4.9\%). Median PFS and OS were 3 and 6.5 months in overall patients. Median OS was 9.7 months when time-to-progression (TTP) during first-line chemotherapy was $>6$ and 5.6 months when it was $<6$ months $(\mathrm{p}=0.04)$. TTP in the first-line therapy was found to be a prognostic factor (34).

Docetaxel and cisplatin are both active in gastric cancer. ECOG 5203: phase II study evaluated the efficacy and toxicity of the combination of sorafenib with docetaxel and cisplatin in the first-line treatment of 44 metastatic or advanced gastric and GEJ adenocarcinoma patients (35). The primary endpoint was RR for the combination. Toxicity, OS and PFS were assessed as secondary endpoints. The PR rate was $41 \%$ (90\% CI, 28-54). The median PFS was 5.8 months (90\% CI, 5.4-7.4 months). The median OS was 13.6 months (90\% CI, 8.6-16.1 months). The major toxicity was neutropenia; $64 \%$ of the patients presented with grade 3-4 neutropenia. One patient experienced hemorrhage at the tumor site. Although the combination of sorafenib, docetaxel and cisplatin has an encouraging efficacy profile with tolerable toxicity, large scale studies of sorafenib with chemotherapy are needed in gastric cancer.

Another phase I-II study of sorafenib in combination with capecitabine and cisplatin (XP) in advanced gastric cancer patients was conducted in the Asian Medical Center (NCT00565370). The study has been completed, but results are not published.

The efficacy and tolerability of sorafenib as second-line treatment in patients with advanced or metastatic gastric cancer who failed from first-line chemotherapy of ECF regimen were studied. The study has been terminated due to low RR, no evidence of PFS or OS improvement (NCT00595985).

Sunitinib. Sunitinib has been found to suppress PDGFR, kit, rearranged during transfection (RET), Flt-3 and VEGFR. A phase II, open-label, multicenter study assessed the efficacy and toxicity of sunitinib as a second-line treatment for patients with advanced gastric or GEJ adenocarcinoma (36). Seventy-eight 
patients received sunitinib $50 \mathrm{mg}$ /day on a schedule $4 / 2$ ( 4 weeks on treatment, followed by 2 weeks off treatment). The trial did not meet the primary endpoint ORR. The rate of partial response (PR) was $2.6 \%$ (2/78), and the best response of SD for $\geq 6$ weeks was $32.1 \%$ (25/78). Median PFS and OS were 2.3 months (95\% CI, 1.6-2.6 months) and 6.8 months $(95 \% \mathrm{CI}$, 4.4-9.6 months). Patients (34.6 and 29.4\%) presented with grade $\geq 3$ thrombocytopenia and neutropenia, respectively. The most common non-hematologic AEs were fatigue, anorexia, nausea, diarrhea and stomatitis. The present study suggested that single-agent sunitinib has insufficient clinical value as secondline treatment for advanced gastric cancer.

Further studies were conducted to research the role of sunitinib in combination with chemotherapy for gastric cancer. Firstly, a phase I, dose-finding study evaluated the maximum tolerated dose (MTD), safety, pharmacokinetics and antitumor activity of sunitinib plus S-1/cisplatin in Japanese patients with advanced/metastatic gastric cancer (37). The MTD of sunitinib was $25 \mathrm{mg}$ /day on schedule $2 / 2$ combined with cisplatin/S-1. The most frequently reported G3/4 AEs were neutropenia (93.8\%) and leukopenia (75.0\%). The ORR was 37.5\%; median PFS was 12.5 months. Six additional patients experienced no disease progression for $\geq 24$ weeks. Another phase I study of sunitinib plus capecitabine/cisplatin or capecitabine/oxaliplatin in advanced gastric cancer also confirmed the same MTD and similar common AEs (38).

A phase I study of sunitinib with irinotecan, 5-fluorouracil and leucovorin (FOLFIRI) for advanced gastroesophageal cancers was conducted in Roswell Park Cancer Institute to study the side-effects and best dose of sunitinib when administered along with FOLFIRI in treating patients with advanced stomach cancer or gastroesophageal cancer (NCT00524186). The study is ongoing, but not recruiting participants.

A randomized phase II trial of sunitinib and docetaxel in 116 advanced gastric cancer or GEJ adenocarcinoma patients (stage IV disease not amenable to surgery, radiation or combined modality therapy with curative intent) who had prior chemotherapy with fluoropyrimidine and platinum, has been completed in Samsung Medical Center, Korea (NCT01238055). The primary endpoint was TTP, and the secondary endpoints were RR, OS and PFS. Results of the trial are expected.

Apatinib. Apatinib is a small-molecule TKI targeting VEGFR-2. A randomized, placebo-controlled, parallel-arm, phase II trial evaluated apatinib for chemotherapy-refractory advanced metastatic gastric cancer (39). A total of 144 patients who experienced treatment failure with at least two chemotherapeutic regimens were randomly assigned to receive placebo, apatinib $850 \mathrm{mg}$ once daily, or apatinib $425 \mathrm{mg}$ twice daily. There were statistically significant differences between the apatinib and placebo groups for both PFS $(\mathrm{p}<0.001)$ and OS $(p<0.001$ and $p=0.0017)$. Nine patients had PR. The most common grade 3-4 AEs were hand-foot syndrome and hypertension. Hence, apatinib showed improved PFS and OS in heavily pretreated patients with metastatic gastric cancer who had experienced treatment failure with two or more chemotherapy regimens.

Results from a multicenter, randomized, double-blind, placebo-controlled phase III trial of apatinib was reported in 2014 at the ASCO meeting (40). Median OS and median PFS were prolonged in the apatinib group compared with the placebo group (195 vs. 140 days, $\mathrm{HR}=0.71$; 95\% CI, 0.54-0.94; $\mathrm{p}<0.016)$ and ( 78 vs. 53 days, $\mathrm{HR}=0.44 ; 95 \% \mathrm{CI}, 0.33-0.61$; $\mathrm{p}<0.0001)$ respectively. The ORR of the apatinib and placebo groups were 2.84 and $0.00 \%$, respectively. Concerning safety, treatment of the apatinib group was generally well tolerated. Grade 3/4 adverse reactions that occurred in $>2 \%$ of patients were hypertension, hand-and-foot syndrome, proteinuria, fatigue, anorexia and elevated aminotransferase. Thus, the efficacy and safety of apatinib in patients with advanced gastric cancer were then further confirmed. The recommended dose for clinical use is $850 \mathrm{mg}$ once daily.

Lapatinib. Lapatinib is a receptor tyrosine kinase inhibitor that inhibits both HER-2 and EGFR. TyTAN was a randomized, phase III study that enrolled 261 HER2-positive patients detected by fluorescence in situ hybridization (FISH). The patients received lapatinib plus paclitaxel or paclitaxel alone. Median OS was 11.0 vs. 8.9 months in the lapatinib plus paclitaxel group vs. the paclitaxel alone group $(\mathrm{p}=0.1044)$, with no significant difference in median PFS (5.4 vs. 4.4 months) or TTP (5.5 vs. 4.4 months). ORR was higher in the lapatinib plus paclitaxel group compared with the paclitaxel alone group (odds ratio [OR], 3.85; $\mathrm{p}<0.001$ ). The subgroup analysis showed that patients with HER2 amplification in IHC3+ had a better efficacy, in the treatment group, compared with IHC0/1+ and $2+$ patients, and a better efficacy was found in Chinese patients compared with Japanese patients (41). However, in another study when the investigator chose patients with HER2 amplification, the lapatinib group did not show effectiveness (42).

\section{5. mTOR inhibitors}

Phosphatidylinositol 3-kinase (PI3K)/Akt and mammalian target of rapamycin (mTOR) are activated in 30 and $60 \%$ of human gastric carcinomas, respectively $(43,44)$. Activation of the PI3K/Akt/mTOR pathway is associated with chemoresistance (43) and worse survival (45-47). These findings suggest that the PI3K/Akt/mTOR pathway is frequently activated in gastric cancer and is directly linked to its progression. Hence, drugs targeting mTOR may improve patient survival.

Everolimus. Everolimus is an oral mTOR inhibitor that binds with high affinity to its intracellular receptor FKBP12 (48). Everolimus has demonstrated antitumor activity in many types of cancers. RAD001, a phase I trial, showed that the combination of capecitabine and everolimus showed tolerable toxicity and modest clinical benefits in refractory gastric cancer patients. The recommended dose of everolimus is $5 \mathrm{mg}$ twice daily (49).

A multicenter phase II study of everolimus in patients with previously treated metastatic gastric cancer enrolled 53 patients. Although neither CR nor PR was obtained, 45\% of the patients showed a decrease in tumor size from baseline. The DCR was 56.0\% (95\% CI, 41.3-70.0\%), median PFS and median OS were 2.7 months (95\% CI, 1.6-3.0 months) and 10.1 months (95\% CI, 6.5-12.1 months), respectively. Common grade 3 or 4 AEs included anemia, hyponatremia, increased glutamyltransferase and lymphopenia. Hence, everolimus 
monotherapy resulted in a satisfactory DCR in patients with previously treated advanced gastric cancer (50).

Results of the randomized, double-blinded, phase III GRANITE-1 study showed that median OS and PFS with everolimus vs. placebo were 5.4 vs. 4.3 months $(p=0.124)$; 1.7 vs. 1.4 months ( $\mathrm{HR}=0.66$; 95\% CI, 0.56-0.78), respectively. Common grade 3/4 AEs included anemia, decreased appetite and fatigue. Thus, compared with best supportive care (BSC), everolimus did not significantly improve OS for advanced gastric cancer that progressed after one or two lines of previous systemic chemotherapy (51).

\section{Anti-MET pathway}

The MET receptor tyrosine kinase is a proto-oncogene that regulates cell growth, survival and migration $(52,53)$. When hepatocyte growth factor (HGF) binds to MET, it leads to dimerization of MET and phosphorylation of tyrosine residues in the kinase domain (Y1230, Y1234 and Y1235), which leads to stimulation of a series of downstream bioactive molecules, and stimulation of cell proliferation, survival and migration (53). Dysregulation of the HGF/MET pathway promotes tumor growth and metastasis.

In gastric cancer, research has found that high expression of c-MET is associated to a greater degree with intestinal than diffuse tumor type $(p=0.04)$, deeper tumor invasion, neural invasion $(\mathrm{p}=0.002)$ and advanced TNM staging (54). Ha et al found that patients with MET overexpression were associated with shorter OS and DFS compared with patients without MET overexpression (55). There was a significant difference in OS between c-MET-positive and c-MET-negative patients (median, 11.9 vs. 14.2 months). Multivariate analysis also showed that c-MET positivity was still a prognostic factor for OS (HR=1.30; 95\% CI, 1.02-1.67; p=0.037) (56). Thus, patients may benefit from therapeutic targeting of the c-MET pathway.

Rilotumumab. Rilotumumab (AMG102) is a fully human monoclonal antibody immunoglobulin G, type 2 (IgG2) against human hepatocyte growth factor/scatter factor (HGF/SF) that blocks the binding of $\mathrm{HGF} / \mathrm{SF}$ to its receptor $\mathrm{MET}$, inhibiting $\mathrm{HGF} / \mathrm{SF} / \mathrm{MET}$-driven activities in cells. Efficacy of the rilotumumab in first-line therapy was evaluated in a phase II trial (57); 121 patients were randomly assigned to an ECX combined with rilotumumab group or a placebo group (40 to rilotumumab $15 \mathrm{mg} / \mathrm{kg}$; 42 to rilotumumab $7.5 \mathrm{mg} / \mathrm{kg}$; 39 to placebo). Median PFS was 5.1 months (95\% CI, 2.9-7.0), 6.8 months (4.5-7.5), 5.7 months (4.5-7.0) and 4.2 months (2.94.9) in the rilotumumab $15 \mathrm{mg} / \mathrm{kg}$ group, rilotumumab $7.5 \mathrm{mg} /$ $\mathrm{kg}$ group, both rilotumumab groups combined, the placebo group, respectively. Hazards ratio analysis of PFS showed an improved prognosis of rilotumumab. Thus, rilotumumab plus ECX showed greater activity than the placebo plus ECX group.

A multicenter, open-label, randomized phase II trial Met or EGFR Inhibition in Gastroesophageal Adenocarcinoma (MEGA) is ongoing in 30 centres in France: FOLFOX alone or in combination with AMG 102 or panitumumab as firstline treatment in patients with advanced gastroesophageal adenocarcinoma (NCT01443065). Patients (162) with no HER2 expression were enrolled. The primary endpoint was PFS at 4 months. Secondary endpoints were PFS, OS, TTP,
ORR, objective response duration, DCR and tolerance of the treatment. The trial divided three arms: Arm A, simplified FOLFOX 4; experimental Arm B, simplified FOLFOX 4 + panitumumab; experimental Arm C, simplified FOLFOX $4+$ AMG 102. The results are expected.

RILOMET-2: a phase III, multicenter, randomized, doubleblind, placebo controlled study of rilotumumab (AMG 102) with cisplatin and capecitabine (CX) as first-line therapy in untreated advanced mesenchymal epithelial transition factor (MET)-positive gastric cancer or GEJ has been conducted (NCT02137343). Tumor MET-positivity was measured by IHC. Primary outcome measures include PFS and OS. Secondary endpoints were TTP, ORR, DCR, time to response (TTR) and incidence of subject adverse events. The present study has been terminated following a pre-planned data monitoring committee safety review of study 20070622.

Onartuzumab. Onartuzumab is a humanized monoclonal antibody directed against MET. An oral presentation of a randomized phase II study of FOLFOX +/- MET inhibitor, onartuzumab in advanced gastroesophageal adenocarcinoma (GEC) was conducted at the 2015 American Society of Clinical Oncology Gastrointestinal Cancer Symposium (ASCO GI). The study showed that no difference was found in either the median PFS in total patients or the median PFS in patients with $\mathrm{MET}^{+}$; the median PFS in overall was 6.77 vs. 6.97 months in the onartuzumab group vs. placebo group $(\mathrm{HR}=1.06 ; 95 \% \mathrm{CI}$, 0.71-1.63; $\mathrm{p}=0.7149$ ); median PFS in patients with $\mathrm{MET}^{+}$was 5.95 vs. 6.8 months in the onartuzumab vs. placebo arms $(\mathrm{HR}=1.38 ; 95 \% \mathrm{CI}, 0.60-3.20 ; \mathrm{p}=0.4514)$. Hence, onartuzumab did not improve PFS for advanced gastric cancer (58).

A randomized, phase III multicenter, double-blind, placebocontrolled study of onartuzumab (MetMAb) in combination with mFOLFOX6 in patients with metastatic HER2-negative and MET-positive gastroesophageal cancer (MetGastric) is ongoing, but not recruiting participants (NCT01662869). The study will evaluate the efficacy and safety of onartuzumab (MetMAb) in combination with mFOLFOX6 in patients with metastatic HER2-negative and MET-positive adenocarcinoma of the stomach or GEJ. Patients (564) will be randomized in a 1:1 ratio to receive either onartuzumab (MetMAb) or placebo in combination with mFOLFOX6. The primary endpoints are $\mathrm{OS}$ in the MET IHC $2+/ 3+$ patient subgroup and OS in the intent-to-treat population, Secondary endpoints are PFS, ORR, safety and quality of life. The results are expected.

Table I summarizes the phase III clinical trials. Fig. 1 shows the agents that act on the various targets discussed.

\section{Other target agents and future directions}

A randomized, double-blinded, multicenter phase II study assessing the efficacy of olaparib (AZD2281, KU-0059436), an orally active poly(ADP-ribose polymerase inhibitor), in combination with paclitaxel vs. paclitaxel alone in patients with recurrent or metastatic gastric cancer and assessing whether low ataxia telangiectasia mutated (ATM) expression, a key activator of DNA damage response, is predictive of improved clinical outcome for olaparib/paclitaxel has been completed (NCT01063517) (59). In the present study, 123 patients received treatment (61 in the olaparib/paclitaxel 
Table I. Phase III clinical trials related to targeted agents for advanced gastric cancer.

\begin{tabular}{|c|c|c|c|c|c|c|c|}
\hline Patients & Agent (Ref.) & Phase & Treatment & $\mathrm{N}$ & $\mathrm{OS}(\mathrm{m})$ & PFS (m) & $\mathrm{RR}$ \\
\hline $\begin{array}{l}\text { Inoperable locally advanced, } \\
\text { recurrent or metastatic }\end{array}$ & Trastuzumab (9) & III & $\begin{array}{l}\text { Chemotherapy, capecitabine/ } \\
\text { fluorouracil + cisplatin }\end{array}$ & 296 & 11.1 & 5.5 & NM \\
\hline $\begin{array}{l}\text { HER2-positive gastric cancer } \\
\text { as a first-line therapy }\end{array}$ & & & Chemotherapy + trastuzumab & 298 & 13.8 & 6.7 & \\
\hline $\begin{array}{l}\text { Untreated, metastatic or } \\
\text { locally advanced }\end{array}$ & Panitumumab (13) & III & $\begin{array}{l}\text { Epirubicin, oxaliplatin and } \\
\text { capecitabine (EOC) }\end{array}$ & 275 & 11.3 & 7.4 & $42 \%$ \\
\hline $\begin{array}{l}\text { esophagogastric } \\
\text { adenocarcinoma }\end{array}$ & & & $\begin{array}{l}\text { Modified-dose } \\
\text { EOC + panitumumab }\end{array}$ & 278 & 8.8 & 6.0 & $46 \%$ \\
\hline $\begin{array}{l}\text { Non-treated advanced } \\
\text { gastric/esophagogastric } \\
\text { junction adenocarcinoma }\end{array}$ & Cetuximab (15) & III & $\begin{array}{l}\text { Capecitabine-cisplatin } \\
\text { Apecitabine-cisplatin } \\
\text { + cetuximab }\end{array}$ & $\begin{array}{l}449 \\
455\end{array}$ & $\begin{array}{r}10.7 \\
9.4\end{array}$ & $\begin{array}{l}5.6 \\
4.4\end{array}$ & $\begin{array}{l}29 \% \\
30 \%\end{array}$ \\
\hline $\begin{array}{l}\text { In the first-line treatment } \\
\text { of advanced gastric cancer } \\
\text { patients (AVAGAST) }\end{array}$ & Bevacizumab (22) & III & $\begin{array}{l}\text { Capecitabine-cisplatin } \\
\text { Capecitabine-cisplatin } \\
+ \text { bevacizumab }\end{array}$ & $\begin{array}{l}387 \\
387\end{array}$ & $\begin{array}{l}12.1 \\
10.1\end{array}$ & $\begin{array}{l}5.3 \\
6.7\end{array}$ & $\begin{array}{r}37.40 \% \\
46 \%\end{array}$ \\
\hline $\begin{array}{l}\text { In Chinese patients with } \\
\text { inoperable locally advanced }\end{array}$ & Bevacizumab (24) & III & $\begin{array}{l}\text { Capecitabine-cisplatin } \\
+ \text { placebo }\end{array}$ & 102 & 11.4 & 6.0 & $33.70 \%$ \\
\hline $\begin{array}{l}\text { or metastatic gastric or } \\
\text { gastroesophageal junction } \\
\text { cancer (AVATAR) }\end{array}$ & & & $\begin{array}{l}\text { Capecitabine-cisplatin } \\
+ \text { bevacizumab }\end{array}$ & 102 & 10.5 & 6.3 & $40.70 \%$ \\
\hline $\begin{array}{l}\text { Patients with metastatic } \\
\text { treatment-refractory } \\
\text { gastric cancer }\end{array}$ & Ramucirumab (26) & III & $\begin{array}{l}\text { Paclitaxel + placebo } \\
\text { Paclitaxel + ramucirumab }\end{array}$ & $\begin{array}{l}330 \\
335\end{array}$ & $\begin{array}{l}7.4 \\
9.6\end{array}$ & NM & NM \\
\hline $\begin{array}{l}\text { Patients who experienced } \\
\text { treatment failure with } \\
\text { at least two chemo- } \\
\text { therapeutic regimens }\end{array}$ & Apatinib (40) & III & $\begin{array}{l}\text { Placebo } \\
\text { Apatinib }\end{array}$ & $\begin{array}{r}90 \\
180\end{array}$ & $\begin{array}{l}140 \text { days } \\
195 \text { days }\end{array}$ & $\begin{array}{l}53 \text { days } \\
78 \text { days }\end{array}$ & $\begin{array}{r}0 \% \\
2.84 \%\end{array}$ \\
\hline $\begin{array}{l}\text { Patients with HER2- } \\
\text { positive by FISH }\end{array}$ & & & Lapatinib + paclitaxel & 11.0 & 5.4 & & \\
\hline $\begin{array}{l}\text { Patients with advanced } \\
\text { gastric cancer who } \\
\text { progressed after one or } \\
\text { two lines of systemic } \\
\text { chemotherapy }\end{array}$ & Everolimus (51) & III & $\begin{array}{l}\text { Placebo + BSC } \\
\text { Everolimus + BSC }\end{array}$ & $\begin{array}{l}215 \\
437\end{array}$ & $\begin{array}{l}4.3 \\
5.4\end{array}$ & $\begin{array}{l}1.4 \\
1.7\end{array}$ & $\begin{array}{l}4.50 \% \\
2.10 \%\end{array}$ \\
\hline
\end{tabular}

Ref., reference number; N, enrolled patient number; m, months; BSC, best supportive care; FISH, fluorescence in situ hybridization; OS, overall survival; PFS, progressive-free survival; RR, responsive rate; NM, not mentioned.

arms; 62 in placebo/paclitaxel arms). The results showed that olaparib/paclitaxel did not lead to a significant improvement in PFS compared with placebo/paclitaxel; the median PFS was 3.91 vs. 3.55 months $(\mathrm{HR}=0.80)$ in the overall population; the median PFS was 5.29 vs. 3.68 months $(\mathrm{HR}=0.74)$ in the $\mathrm{ATM}_{\text {low }}$ population. However, olaparib/paclitaxel significantly improved OS compared with placebo/paclitaxel in both the overall population $(\mathrm{HR}=0.56 ; 80 \% \mathrm{CI}, 0.41-0.75 ; \mathrm{p}=0.005$; median OS, 13.1 vs. 8.3 months, respectively) and the $\mathrm{ATM}_{\text {low }}$ population $(\mathrm{HR}=0.35 ; 80 \% \mathrm{CI}, 0.22-0.56$; $\mathrm{p}=0.002$; median OS, not reached vs. 8.2 months, respectively). Olaparib/paclitaxel was generally well tolerated, with no unexpected safety findings. A randomized, double-blinded, placebo controlled, multicenter phase III study is underway
(NCT01924533). The study is to assess the efficacy and safety of olaparib in combination with paclitaxel, compared to placebo in combination with paclitaxel, in Asian patients with advanced gastric cancer (including GEJ) in second-line therapy. Patients (500) will be enrolled.

Pyrotinib is an oral tyrosine kinase inhibitor targeting both EGFR and HER-2 receptors. A phase I study of pyrotinib has been designed to evaluate the safety and tolerability of pyrotinib or pyrotinib in combination with docetaxel in patients with HER2-positive advanced gastric cancer. The study is still recruiting (NCT02378389).

A randomized, open-label, multi-center phase II study to compare AUY922, an HSP90 inhibitor, with docetaxel or irinotecan in adult patients with advanced gastric cancer 


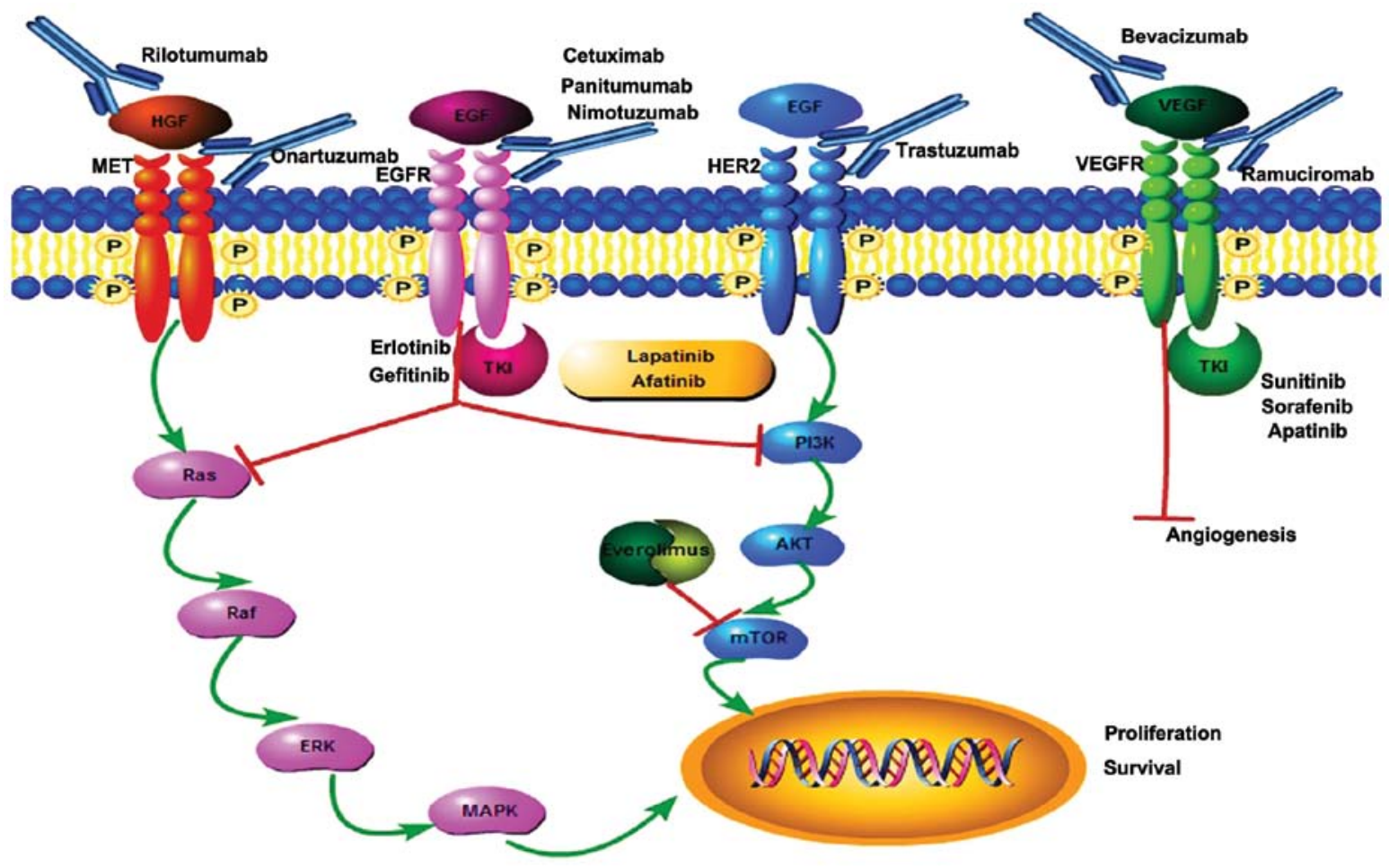

Figure 1. Agents that act on various molecular targets in gastric cancer.

who have progressed after first-line of chemotherapy has been completed (NCT01084330) and results are expected.

Pertuzumab, an anti-HER2 humanized monoclonal antibody that inhibits receptor dimerization, has a mechanism of action that is complementary to that of trastuzumab (60), and combination therapy with the two antibodies has shown promising activity in phase III studies involving patients with HER2-positive breast cancer. A well known phase III clinical trial is the CLEOPATRA study. Compared with the control group (placebo plus trastuzumab plus docetaxel), there was an improvement of 6.1 months of the median PFS in the pertuzumab plus trastuzumab plus docetaxel group (18.5 vs. 12.4 months) (61), and an improvement of 15.7 months of median OS in the pertuzumab plus trastuzumab plus docetaxel group (56.5 vs. 40.8 months) and with long-term cardiac safety maintained (62). The successful treatment modalities of the double targeting of HER-2 in HER-2-positive breast cancer suggests that patients with HER-2-positive gastric cancer could also benefit from pertuzumab plus trastuzumab plus chemotherapy. In addition, a phase IIa study of the pharmacokinetics and safety of pertuzumab plus trastuzumab and chemotherapy in advanced gastric cancer has been conducted (63). In addition, based on the pharmacokinetic and safety data, the $840 \mathrm{mg}$ q3w pertuzumab dose has been selected for a phase III study of pertuzumab, trastuzumab and chemotherapy in HER2positive adenocarcinoma of gastric cancer (NCT01774786).

\section{Conclusions}

In the past few years, although great efforts have been made to improve the survival of patients with gastric cancer through targeted therapy, fewer benefits have been brought to gastric cancer patients than other cancers. Combination of trastuzumab and chemotherapy is now considered as a standard first-line treatment for patients with HER2-overexpressing advanced gastric cancer, and ramucirumab could be considered as a standard second-line treatment. Based on clinical trial data, apatinib may be considered as a preferable treatment for advanced gastric cancer patients who failed from at least two chemotherapeutic regimens. There is still lack of phase III clinical trials in gastric cancer patients who may benefit from TKI agents. Agents targeting human EGFR remain very controversial in gastric cancer therapy. The key reason is that participants in the clinical trials of new targeted agents were not selected by detection of the targeted molecule. Although everolimus monotherapy resulted in a satisfactory DCR in a phase II clinical trial, the phase III GRANITE-1 study showed negative results in terms of patient benefit from the treatment with everolimus compared with a placebo. Results of the treatment modalities of the double targeting of HER-2, that is pertuzumab plus trastuzumab plus chemotherapy are expected. Given that obvious heterogeneity exists in gastric cancer patients, targeted therapy must be individualized, thus deeper insight into the molecular characteristics of gastric cancer is urgently needed.

\section{Acknowledgements}

We acknowledge the highly qualified native English speaking editors at MedSci.

\section{References}

1. Ferlay J, Soerjomataram I, Ervik M, Dikshit R, Eser S, Mathers C, Rebelo M, Parkin DM, Forman D and Bray F: Cancer incidence and mortality worldwide: Sources, methods and major patterns in GLOBOCAN 2012. Int J Cancer 136: E359-E386, 2015. 
2. Schlessinger J: Ligand-induced, receptor-mediated dimerization and activation of EGF receptor. Cell 110: 669-672, 2002.

3. Riese DJ II and Stern DF: Specificity within the EGF family/ ErbB receptor family signaling network. BioEssays 20: 41-48, 1998.

4. Yarden Y and Sliwkowski MX: Untangling the ErbB signalling network. Nat Rev Mol Cell Biol 2: 127-137, 2001.

5. Tang J, Liu N and Zhuang S: Role of epidermal growth factor receptor in acute and chronic kidney injury. Kidney Int 83: 804-810, 2013

6. Kim MA, Lee HS, Lee HE, Jeon YK, Yang HK and Kim WH EGFR in gastric carcinomas: Prognostic significance of protein overexpression and high gene copy number. Histopathology 52 : 738-746, 2008

7. Langer R, Von Rahden BH, Nahrig J, Von Weyhern C, Reiter R, Feith M, Stein HJ, Siewert JR, Höfler H and Sarbia M: Prognostic significance of expression patterns of c-erbB-2, p53, p16INK4A p27KIP1, cyclin D1 and epidermal growth factor receptor in oesophageal adenocarcinoma: A tissue microarray study. J Clin Pathol 59: 631-634, 2006

8. Lieto E, Ferraraccio F, Orditura M, Castellano P, Mura AL, Pinto M, Zamboli A, De Vita F and Galizia G: Expression of vascular endothelial growth factor (VEGF) and epidermal growth factor receptor (EGFR) is an independent prognostic indicator of worse outcome in gastric cancer patients. Ann Surg Oncol 15: 69-79, 2008.

9. Bang YJ, Van Cutsem E, Feyereislova A, Chung HC, Shen L, Sawaki A, Lordick F, Ohtsu A, Omuro Y, Satoh T, et al; ToGA Trial Investigators: Trastuzumab in combination with chemotherapy versus chemotherapy alone for treatment of HER2-positive advanced gastric or gastro-oesophageal junction cancer (ToGA): A phase 3, open-label, randomised controlled trial. Lancet 376: 687-697, 2010.

10. Ryu MH, Yoo C, Kim JG, Ryoo BY, Park YS, Park SR, Han HS, Chung IJ, Song EK, Lee KH, et al: Multicenter phase II study of trastuzumab in combination with capecitabine and oxaliplatin for advanced gastric cancer. Eur J Cancer 51: 482-488, 2015

11. Chua C, Tan IB, Yamada Y, Rha SY, Yong WP, Ong WS, Tham CK, Ng M, Tai DW, Iwasa S, et al: Phase II study of trastuzumab in combination with S-1 and cisplatin in the firstline treatment of human epidermal growth factor receptor HER2-positive advanced gastric cancer. Cancer Chemother Pharmacol 76: 397-408, 2015.

12. Douillard JY, Siena S, Cassidy J, Tabernero J, Burkes R, Barugel M, Humblet Y, Bodoky G, Cunningham D, Jassem J, et al: Randomized, phase III trial of panitumumab with infusional fluorouracil, leucovorin, and oxaliplatin (FOLFOX4) versus FOLFOX4 alone as first-line treatment in patients with previously untreated metastatic colorectal cancer: The PRIME study. J Clin Oncol 28: 4697-4705, 2010.

13. Waddell T, Chau I, Cunningham D, Gonzalez D, Okines AF Okines C, Wotherspoon A, Saffery C, Middleton G, Wadsley J, et al: Epirubicin, oxaliplatin, and capecitabine with or without panitumumab for patients with previously untreated advanced oesophagogastric cancer (REAL3): A randomised, open-label phase 3 trial. Lancet Oncol 14: 481-489, 2013.

14. Zhang X, Xu J, Liu H, Yang L, Liang J, Xu N, Bai Y, Wang J and Shen L: Predictive biomarkers for the efficacy of cetuximab combined with cisplatin and capecitabine in advanced gastric or esophagogastric junction adenocarcinoma: A prospective multicenter phase 2 trial. Med Oncol 31: 226, 2014.

15. Lordick F, Kang YK, Chung HC, Salman P, Oh SC, Bodoky G, Kurteva G, Volovat C, Moiseyenko VM, Gorbunova V, et al Arbeitsgemeinschaft Internistische Onkologie and EXPAND Investigators: Capecitabine and cisplatin with or without cetuximab for patients with previously untreated advanced gastric cancer (EXPAND): A randomised, open-label phase 3 trial. Lancet Oncol 14: 490-499, 2013.

16. Xu CD: Clinical study of nimotuzumab combined with chemotherapy in the treatment of late stage gastric cancer. Asian Pac J Cancer Prev 15: 10273-10276, 2014

17. Gupta MK and Qin RY: Mechanism and its regulation of tumorinduced angiogenesis. World J Gastroenterol 9: 1144-1155, 2003.

18. Hanahan D and Weinberg RA: Hallmarks of cancer: The next generation. Cell 144: 646-674, 2011.

19. Kim KJ, Li B, Winer J, Armanini M, Gillett N, Phillips HS and Ferrara N: Inhibition of vascular endothelial growth factor-induced angiogenesis suppresses tumour grow th in vivo. Nature 362: 841-844, 1993
20. Ferrara N, Hillan KJ, Gerber HP and Novotny W: Discovery and development of bevacizumab, an anti-VEGF antibody for treating cancer. Nat Rev Drug Discov 3: 391-400, 2004.

21. Uronis HE, Bendell JC, Altomare I, Blobe GC, Hsu SD, Morse MA, Pang H, Zafar SY, Conkling P, Favaro J, et al: A phase II study of capecitabine, oxaliplatin, and bevacizumab in the treatment of metastatic esophagogastric adenocarcinomas. Oncologist 18: 271-272, 2013

22. Ohtsu A, Shah MA, Van Cutsem E, Rha SY, Sawaki A, Park SR, Lim HY, Yamada Y, Wu J, Langer B, et al: Bevacizumab in combination with chemotherapy as first-line therapy in advanced gastric cancer: A randomized, double-blind, placebo-controlled phase III study. J Clin Oncol 29: 3968-3976, 2011.

23. Van Cutsem E, de Haas S, Kang YK, Ohtsu A, Tebbutt NC, Ming Xu J, Peng Yong W, Langer B, Delmar P, Scherer SJ, et al: Bevacizumab in combination with chemotherapy as first-line therapy in advanced gastric cancer: A biomarker evaluation from the AVAGAST randomized phase III trial. J Clin Oncol 30: 2119-2127, 2012.

24. Shen L, Li J, Xu J, Pan H, Dai G, Qin S, Wang L, Wang J, Yang Z, Shu Y, et al: Bevacizumab plus capecitabine and cisplatin in Chinese patients with inoperable locally advanced or metastatic gastric or gastroesophageal junction cancer: Randomized, double-blind, phase III study (AVATAR study). Gastric Cancer 18: 168-176, 2015.

25. Spratlin JL, Cohen RB, Eadens M, Gore L, Camidge DR, Diab S, Leong S, O'Bryant C, Chow LQ, Serkova NJ, et al: Phase I pharmacologic and biologic study of ramucirumab (IMC-1121B), a fully human immunoglobulin G1 monoclonal antibody targeting the vascular endothelial growth factor receptor-2. J Clin Oncol 28: 780-787, 2010.

26. Fuchs CS, Tomasek J, Yong CJ, Dumitru F, Passalacqua R, Goswami C, Safran H, dos Santos LV, Aprile G, Ferry DR, et al; REGARD Trial Investigators: Ramucirumab monotherapy for previously treated advanced gastric or gastro-oesophageal junction adenocarcinoma (REGARD): An international, randomised, multicentre, placebo-controlled, phase 3 trial. Lancet 383: 31-39, 2014.

27. Wilke H, Muro K, Van Cutsem E, Oh SC, Bodoky G, Shimada Y, Hironaka S, Sugimoto N, Lipatov O, Kim TY, et al; RAINBOW Study Group: Ramucirumab plus paclitaxel versus placebo plus paclitaxel in patients with previously treated advanced gastric or gastro-oesophageal junction adenocarcinoma (RAINBOW): A double-blind, randomised phase 3 trial. Lancet Oncol 15: 1224-1235, 2014.

28. Yoon HH, Bendell JC, Braiteh FS, Firdaus I, Philip PA, Cohn AL Lewis N, Anderson DM, Arrowsmith E, Schwartz JD, et al: Ramucirumab (RAM) plus FOLFOX as front-line therapy (Rx) for advanced gastric or esophageal adenocarcinoma (GE-AC): Randomized, double-blind, multicenter phase 2 trial. J Clin Oncol 32 (Suppl 5s): 4004, 2014

29. Bezjak A, Tu D, Seymour L, Clark G, Trajkovic A, Zukin M, Ayoub J, Lago S, de Albuquerque Ribeiro R, Gerogianni A, et al; National Cancer Institute of Canada Clinical Trials Group Study BR.21: Symptom improvement in lung cancer patients treated with erlotinib: Quality of life analysis of the National Cancer Institute of Canada Clinical Trials Group Study BR.21. J Clin Oncol 24: 3831-3837, 2006.

30. Shepherd FA, Rodrigues Pereira J, Ciuleanu T, Tan EH, Hirsh V, Thongprasert S, Campos D, Maoleekoonpiroj S, Smylie M, Martins R, et al; National Cancer Institute of Canada Clinical Trials Group: Erlotinib in previously treated non-small-cell lung cancer. N Engl J Med 353: 123-132, 2005.

31. Motzer RJ, Hutson TE, Tomczak P, Michaelson MD, Bukowski RM, Rixe O, Oudard S, Negrier S, Szczylik C, Kim ST, et al: Sunitinib versus interferon alfa in metastatic renal-cell carcinoma. N Engl J Med 356: 115-124, 2007.

32. Llovet JM, Ricci S, Mazzaferro V, Hilgard P, Gane E, Blanc JF, de Oliveira AC, Santoro A, Raoul JL, Forner A, et al; SHARP Investigators Study Group: Sorafenib in advanced hepatocellular carcinoma. N Engl J Med 359: 378-390, 2008.

33. Cheng AL, Kang YK, Chen Z, Tsao CJ, Qin S, Kim JS, Luo R, Feng J, Ye S, Yang TS, et al: Efficacy and safety of sorafenib in patients in the Asia-Pacific region with advanced hepatocellular carcinoma: A phase III randomised, double-blind, placebo-controlled trial. Lancet Oncol 10: 25-34, 2009. 
34. Martin-Richard M, Gallego R, Pericay C, Garcia Foncillas J, Queralt B, Casado E, Barriuso J, Iranzo V, Juez I, Visa L, et al: Multicenter phase II study of oxaliplatin and sorafenib in advanced gastric adenocarcinoma after failure of cisplatin and fluoropyrimidine treatment. A GEMCAD study. Invest New Drugs 31: 1573-1579, 2013.

35. Sun W, Powell M, O'Dwyer PJ, Catalano P, Ansari RH and Benson AB III: Phase II study of sorafenib in combination with docetaxel and cisplatin in the treatment of metastatic or advanced gastric and gastroesophageal junction adenocarcinoma: ECOG 5203. J Clin Oncol 28: 2947-2951, 2010.

36. Bang YJ, Kang YK, Kang WK, Boku N, Chung HC, Chen JS, Doi T, Sun Y, Shen L, Qin S, et al: Phase II study of sunitinib as second-line treatment for advanced gastric cancer. Invest New Drugs 29: 1449-1458, 2011.

37. Boku N, Muro K, Machida N, Hashigaki S, Kimura N, Suzuki M, Lechuga $M$ and Miyata Y: Phase I study of sunitinib plus $S-1$ and cisplatin in Japanese patients with advanced or metastatic gastric cancer. Invest New Drugs 32: 261-270, 2014.

38. Lee KW, Park SR, Oh DY, Park YI, Khosravan R, Lin X, Lee SY Roh EJ, Valota O, Lechuga MJ, et al: Phase I study of sunitinib plus capecitabine/cisplatin or capecitabine/oxaliplatin in advanced gastric cancer. Invest New Drugs 31: 1547-1558, 2013.

39. Li J, Qin S, Xu J, Guo W, Xiong J, Bai Y, Sun G, Yang Y, Wang L, Xu N, et al: Apatinib for chemotherapy-refractory advanced metastatic gastric cancer: Results from a randomized, placebo-controlled, parallel-arm, phase II trial. J Clin Oncol 31: 3219-3225, 2013

40. Qin Sk; PLA Cancer Center of Nanjing Bayi Hospital, Nanjing, China: Phrase III study of apatinib in advanced gastric cancer: A randomized double-blind, placebo-controlled trial. J Clin Oncol 32 (Suppl 5s): 4003, 2014.

41. Satoh T, Xu RH, Chung HC, Sun GP, Doi T, Xu JM, Tsuji A, Omuro Y, Li J, Wang JW, et al: Lapatinib plus paclitaxel versus paclitaxel alone in the second-line treatment of HER2-amplified advanced gastric cancer in Asian populations: TyTAN - a randomized, phase III study. J Clin Oncol 32: 2039-2049, 2014.

42. A Phase III study of ERBB2 positive advanced or metastatic gastric or esophageal or gastroesophageal junction adenocarcinoma treated with capecitabine plus oxaliplatin with or without lapatinib. J Clin Oncol 31 (Suppl): LBA4001, 2013.

43. Oki E, Baba H, Tokunaga E, Nakamura T, Ueda N, Futatsugi M, Mashino K, Yamamoto M, Ikebe M, Kakeji Y, et al: Akt phosphorylation associates with LOH of PTEN and leads to chemoresistance for gastric cancer. Int J Cancer 117: 376-380, 2005.

44. Lang SA, Gaumann A, Koehl GE, Seidel U, Bataille F, Klein D, Ellis LM, Bolder U, Hofstaedter F, Schlitt HJ, et al: Mammalian target of rapamycin is activated in human gastric cancer and serves as a target for therapy in an experimental model. Int J Cancer 120: 1803-1810, 2007.

45. Xu DZ, Geng QR, Tian Y, Cai MY, Fang XJ, Zhan YQ, Zhou ZW, Li W, Chen YB, Sun XW, et al: Activated mammalian target of rapamycin is a potential therapeutic target in gastric cancer. BMC Cancer 10: 536, 2010

46. Yu G, Wang J, Chen Y, Wang X, Pan J, Li G, Jia Z, Li Q, Yao JC and Xie K: Overexpression of phosphorylated mammalian target of rapamycin predicts lymph node metastasis and prognosis of Chinese patients with gastric cancer. Clin Cancer Res 15: $1821-1829,2009$

47. An JY, Kim KM, Choi MG, Noh JH, Sohn TS, Bae JM and Kim S: Prognostic role of p-mTOR expression in cancer tissues and metastatic lymph nodes in pT2b gastric cancer. Int J Cancer 126: 2904-2913, 2010

48. Wan X and Helman LJ: The biology behind mTOR inhibition in sarcoma. Oncologist 12: 1007-1018, 2007.

49. Lim T, Lee J, Lee DJ, Lee HY, Han B, Baek KK, Ahn HK, Lee SJ, Park SH, Park JO, et al: Phase I trial of capecitabine plus everolimus (RAD001) in patients with previously treated metastatic gastric cancer. Cancer Chemother Pharmacol 68: 255-262, 2011.
50. Doi T, Muro K, Boku N, Yamada Y, Nishina T, Takiuchi H, Komatsu Y, Hamamoto Y, Ohno N, Fujita Y, et al: Multicenter phase II study of everolimus in patients with previously treated metastatic gastric cancer. J Clin Oncol 28: 1904-1910, 2010.

51. Ohtsu A, Ajani JA, Bai YX, Bang YJ, Chung HC, Pan HM, Sahmoud T, Shen L, Yeh KH, Chin K, et al: Everolimus for previously treated advanced gastric cancer: Results of the randomized, double-blind, phase III GRANITE-1 study. J Clin Oncol 31: 13935-13943, 2013.

52. Slørdahl TS, Denayer T, Moen SH, Standal T, Børset M, Ververken C and Rø TB: Anti-c-MET nanobody - a new potential drug in multiple myeloma treatment. Eur J Haematol 91: 399-410, 2013.

53. Stellrecht CM and Gandhi V: MET receptor tyrosine kinase as a therapeutic anticancer target. Cancer Lett 280: 1-14, 2009.

54. Sotoudeh K, Hashemi F, Madjd Z, Sadeghipour A, Molanaei S and Kalantary E: The clinicopathologic association of c-MET overexpression in Iranian gastric carcinomas; an immunohistochemical study of tissue microarrays. Diagn Pathol 7: 57, 2012.

55. Ha SY, Lee J, Kang SY, Do IG, Ahn S, Park JO, Kang WK, Choi MG, Sohn TS, Bae JM, et al: MET overexpression assessed by new interpretation method predicts gene amplification and poor survival in advanced gastric carcinomas. Mod Pathol 26: $1632-1641,2013$

56. Fuse N, Kuboki Y, Kuwata T, Nishina T, Kadowaki S, Shinozaki E, Machida N, Yuki S, Ooki A, Kajiura S, et al: Prognostic impact of HER2, EGFR, and c-MET status on overall survival of advanced gastric cancer patients. Gastric Cancer: Feb 15, 2015 (Epub ahead of print).

57. Iveson T, Donehower RC, Davidenko I, Tjulandin S, Deptala A, Harrison M, Nirni S, Lakshmaiah K, Thomas A, Jiang Y, et al: Rilotumumab in combination with epirubicin, cisplatin, and capecitabine as first-line treatment for gastric or oesophagogastric junction adenocarcinoma: An open-label, dose de-escalation phase $1 \mathrm{~b}$ study and a double-blind, randomised phase 2 study. Lancet Oncol 15: 1007-1018, 2014.

58. Shah MA, Cho JY, Huat ITB, Tebbutt NC, Yen CJ, Kang A, Shames DS, Bu L and Kang YK: Randomized phase II study of FOLFOX/- MET inhibitor, onartuzumab (O), in advanced gastroesophageal adenocarcinoma (GEC). J Clin Oncol 33: (abstract 2), 2015.

59. Bang YJ, Im SA, Lee KW, Cho JY, Song EK, Lee KH, Kim YH, Park JO, Chun HG, Zang DY, et al: Randomized, double-blind phase II trial with prospective classification by ATM protein level to evaluate the efficacy and tolerability of olaparib plus paclitaxel in patients with recurrent or metastatic gastric cancer. J Clin Oncol 33: 3858-3865, 2015.

60. Malenfant SJ, Eckmann KR and Barnett CM: Pertuzumab: A new targeted therapy for HER2-positive metastatic breast cancer. Pharmacotherapy 34: 60-71, 2014.

61. Baselga J, Cortés J, Kim SB, Im SA, Hegg R, Im YH, Roman L, Pedrini JL, Pienkowski T, Knott A, et al; CLEOPATRA Study Group: Pertuzumab plus trastuzumab plus docetaxel for metastatic breast cancer. N Engl J Med 366: 109-119, 2012.

62. Swain SM, Baselga J, Kim SB, Ro J, Semiglazov V, Campone M, Ciruelos E, Ferrero JM, Schneeweiss A, Heeson S, et al; CLEOPATRA Study Group: Pertuzumab, trastuzumab, and docetaxel in HER2-positive metastatic breast cancer. N Engl J Med 372: 724-734, 2015.

63. Kang YK, Rha SY, Tassone P, Barriuso J, Yu R, Szado T, Garg A and Bang YJ: A phase IIa dose-finding and safety study of firstline pertuzumab in combination with trastuzumab, capecitabine and cisplatin in patients with HER2-positive advanced gastric cancer. Br J Cancer 111: 660-666, 2014. 